\section{The effect of Pavlovian CS+ and CS- on exploratory behavior}

\author{
P. MIKULKA, P. KENDALL, J. CONSTANTINE \\ and L. PORTERFIELD \\ Old Dominion University, Norfolk, Va. 23508
}

This experiment was designed to examine the effects of Pavlovian conditioned fear (CS+) and safety (CS-) stimuli on open-field behavior. The presence of the CS+ reduced exploration and increased freezing time and the amount of defecation, while the CS- increased exploratory activity and reduced signs of fear. A nonshocked group was used to assess the general effects of preshock on subsequent exploration. In general, shock exposure prior to testing reduced exploration.

Rescorla (1969) has proposed that the critical factor in Pavlovian conditioning is the contingency established between the CS and US. In essence, a stimulus which is consistently paired with the occurrence of an electric shock becomes a conditioned fear stimulus (CS+), while a stimulus that is explicitly unpaired with shock becomes a predictor of a nonshock period and a conditioned safety stimulus (CS-). The effect of these contingencies is assessed against a control group exposed to a truly random CS-US contingency, which might be expected to reduce the possibility of any associative connection being made between the CS and US. The truly random contingency represents a psychological zero point on the conditioned fear-safety dimension. The most commonly used procedure for examining the efficacy of a Pavlovian conditioned stimulus is to introduce it during an ongoing shock-motivated task (i.e., Sidman avoidance). In this context, the CS+ reliably potentiates avoidance responding, whereas the presentation of the CS- depresses avoidance responding (Bull \& Overmier, 1968; Weisman \& Litner, 1971). This latter effect is interpreted as reflecting the inhibition of fear by the CS-. Behavioral observations have reported a general relaxation of $\mathrm{Ss}$ during the presence of the $\mathrm{CS}$ (Rescorla \& Lolordo, 1965).

In this experiment, a Pavlovian CSbased on a noncontingency with shock is transferred to an open-field environment in order to examine the generalization of its fear-inhibiting properties to fear produced by a novel situation. Based on the simple assumption that fear inhibits exploration (Montgomery, 1955), a CS- presented during open-field exposure should result in an increased level of activity, whereas the CS+ should produce a reduced level of exploration. A similar increase in exploratory activity was observed in an open field with the presentation of a conditioned appetitive stimulus (Bindra \& Palfai, 1967). The present design also includes a nonshocked group to examine the general effect of preexposure to shock on subsequent exploratory behavior and emotionality.

\section{SUBJECTS}

The Ss were 24 male albino rats raised in our laboratory. The $\mathrm{Ss}$ weighed $300-350 \mathrm{~g}$ at the start of the experiment. All Ss were individually housed and maintained on ad lib food and water regimen throughout the study.

\section{APPARATUS}

The conditioning apparatus consisted of four individual chambers. Each chamber was $11 \times 5.5 \times 12$ in. (height, width, and length), with a 4 -in. speaker set in the chamber cover. The floor consisted of stainless steel rods set at $1 / 2$-in. intervals. The open field was a $17 \times 45 \times 45$ in. wood enclosure. The floors and walls were divided into 15 -in. squares painted in a checkerboard black and white pattern, which resulted in nine equal squares on the floor. Mounted 17 in. above the center of the field were four speakers placed to produce a homogeneous sound field. In the center of the speakers, four $7 \frac{1}{2}-\mathrm{W}$ clear light bulbs were set to flash at approximately 5-sec-off $/ 5$-sec-on intervals. Suspended 36 in. above the field was a $25-W$ red light used for continuous observation of the Ss.

\section{PROCEDURE}

The Ss were assigned randomly to the four experimental groups $(N=6)$. All treatment conditions received identical CS sequences. The CS was a $60-$ sec $1,000-\mathrm{Hz} 80-\mathrm{dBA}$ tone. The CS was programmed with an average ITI of $4 \mathrm{~min}$. The US was a $1.6-\mathrm{mA} .75-\mathrm{sec}$ scrambled shock. The fear group received the US once during each CS presentation (a CS-US contingency of 1.00). The safety group never received the US during or within 1 min of the beginning or end of the CS (a CS-US contingency of 0.00 ). The TRC group had shocks presented randomly during each daily session. The number of chance CS-US pairings was recorded and yielded a mean contingency of 0.24 . The tone group never received the US.

The Ss were handled $5 \mathrm{~min}$ a day for 2 weeks prior to the start of conditioning. Conditioning consisted of five consecutive daily sessions. Each day, $10 \mathrm{CS}$ and 10 US presentations were programmed within the daily 50-min session, with the exception of the tone condition that only received the CS.

On the 3 rd, 5 th, and 7 th days after the completion of conditioning, the Ss were tested for $10 \mathrm{~min}$ in the open field. Each test consisted of the $S$ being placed in the middle of the field with the training CS presented continuously. The flashing lights were used during each test. Activity was determined by the number of squares entered by the $S$. An entrance was defined as the $S$ bringing all four legs into a given square. At the end of each test, the number of boli was recorded. An $E$ judged freezing time by depressing a button that activated a Standard Electric timer. This judge never knew to what group the Ss being placed in the open field belonged. Freezing was defined as whole-body immobility and a minimum of vibrissae movement. Each day of testing and training the $S s$ were randomly assigned their positions in the daily sequence.

\section{RESULTS}

Activity (Squares Entered)

An analysis of variance on activity yielded a significant main effect for groups $(F=6.902, \quad d f=3 / 20$, $\mathrm{p}<.005)$. Duncan's range test revealed that the tone group was more active than any of the other groups, with the safety group significantly more active than the fear and TRC groups, which were not significantly different from each other (unless

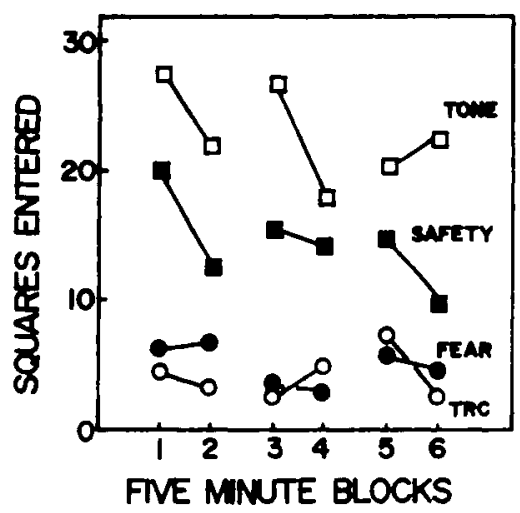

Fig. 1. The mean number of squares entered for the four experimental groups over the six blocks of testing. 

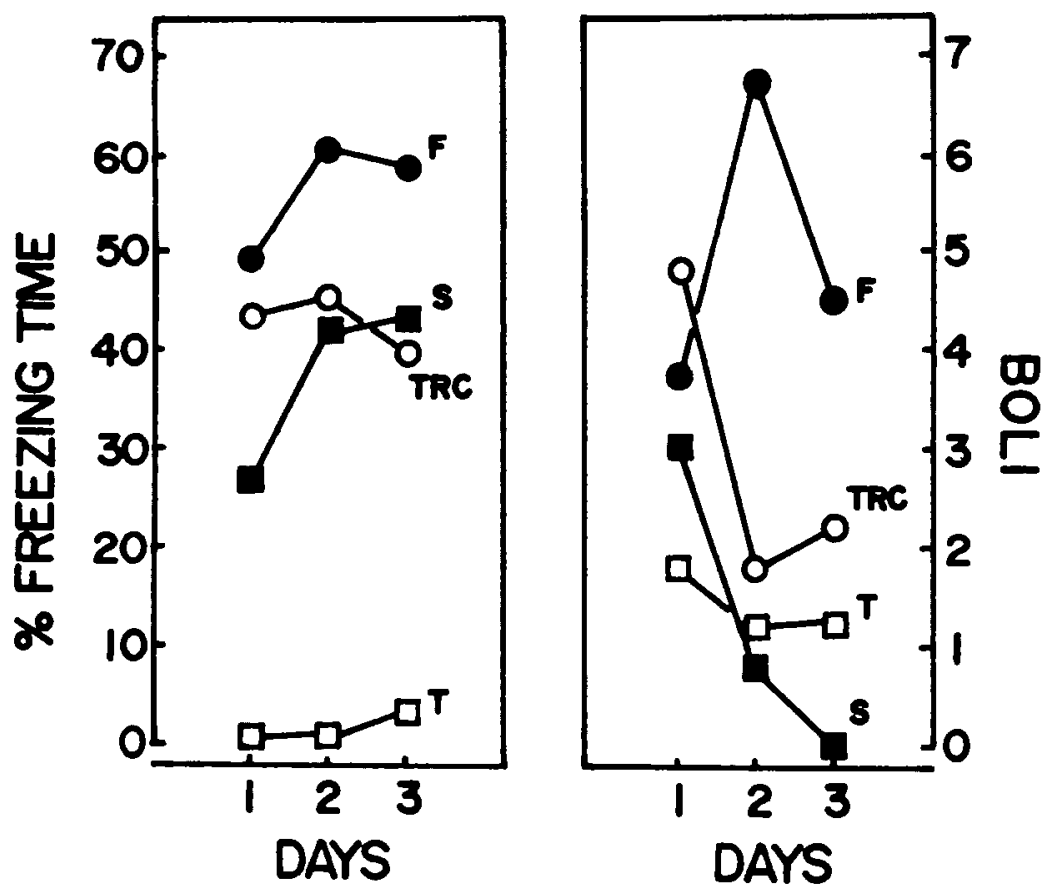

Fig. 2. The mean percentage of freezing time and the mean number of boli observed over the 3 days of testing.

otherwise stated, all range comparisons are significant at the .01 level). The observed activity differences were remarkably consistent across test periods, and this is reflected by the nonsignificant blocks and Groups by Blocks effects (Fig. 1).

\section{Defecation}

An analysis of variance performed on defecation over the 3 days of testing yielded a significant groups effect $(F=5.798, \mathrm{df}=3 / 20, \mathrm{p}<.01)$, with a nonsignificant days effects, while the Groups by Days interaction just missed significance $(\mathrm{F}=2.250$, $\mathrm{df}$ $=6 / 40, p<.10)$. This latter effect reflects the decrease in emotionality of the TRC and safety groups across exposure days, while the tone and fear groups failed to evidence any change in emotionality (Fig. 2). Range tests showed that the fear group defecated more than all other groups. The TRC group evidenced an intermediate level of defecation that was significantly greater than the tone or safety group $(p<.05)$. The tone and safety groups showed little defecation and were not significantly different from each other. Freezing

A significant groups effect $(\mathrm{F}=$ $5.345, \mathrm{df}=3 / 20, \mathrm{p}<.01$ ) was obtained using an analysis of variance on the percentage of freezing time. However, the days and the Groups by Days effects were nonsignificant. Range tests showed that the fear and TRC groups were not different from each other, but both froze significantly more than the tone control group (Fig. 2). The safety group evidenced less freezing than the fear group $(p<.05)$ and was not froze more than the tone group, which showed little freezing behavior.

\section{Interrelationships}

Among Measures

Rank-order correlations were computed for all combinations of the three behavioral measures, and all were significant $(\mathrm{p}<.01, \mathrm{df}=24)$. The correlation between the number of squares entered and the percentage of freezing time yielded the expected negative relationship ( -.81$)$. A strong negative relationship was found between the amount of defecation (emotional arousal) and the number of squares entered $(-.82)$, and a positive correlation $(+.62)$ was found between the amount of defecation and the percentage of freezing time.

\section{DISCUSSION}

Freezing and defecation are frequently used indicators of fear (Aitken, 1970; Livesey \& Egger, 1970), and, within the present study, a strong positive correlation was found between freezing and defecation. Further, both fear indices were negatively correlated with activity. Open-field activity, therefore, appears to be inversely related to fear levels. In agreement with this are the findings that the fear Ss defecated the most and were the least active, while the safety Ss were significantly more active, froze less, and showed little defecation. different from the TRC group, but
The behavior of the safety Ss, when compared to that of the TRC controls, supports the hypothesis that a stimulus that predicts a shock-free period acquires fear inhibitory properties. The safety $\mathrm{Ss}$ were more active and defecated less than the TRC Ss. Also, the defecation levels of the safety Ss tended to be less than that of the tone Ss that had never received electric shock. Although the results confirmed the experimental hypothesis, it had been expected that the safety Ss would display greater behavioral differences from the TRC controls. It is possible that the use of the "contrast" conditioning procedure does not produce as robust a $\mathrm{CS}-$ as the more commonly used Pavlovian discriminative procedure. However, contrast conditioning procedures have successfully produced a CS-, though the relative efficacy of the procedures has not been well established (Rescorla \& Lolordo, 1965; Weisman \& Litner, 1969). Another consideration is that a CS- takes longer to establish than a $\mathrm{CS}+$, requiring from 40 to $60 \mathrm{US}-\mathrm{CS}$ pairings to produce significant results, and while the Ss in the present design received 50 such pairings, stronger behavioral effects might have emerged given additional training.

Comparisons of the TRC and fear Ss indicated differences in the expected direction for two of the three behavioral measures. The fear Ss defecated more and had a greater percentage of freezing time than the TRC Ss, but there was no difference in the number of squares entered. However, although there was little ambulation by the TRC Ss, they were considerably more active (i.e., sniffing, rearing) than the fear $\mathrm{Ss}$, as suggested by the $10 \%-20 \%$ difference in freezing time each test period.

The results showed that the CS+ and $\mathrm{CS}^{-}$are effective when transferred to the novel environment, and this occurred despite the change in CS duration from 1 to $10 \mathrm{~min}$. The CS+ was remarkably durable over the three periods of testing in maintaining high levels of arousal with no apparent attenuation.

Finally, the behavior of the shocked vs the nonshocked Ss suggested a greater emotionality of the former as evidenced by the lower activity levels and increased freezing times. Apparently, experience with electric shock within this experimental paradigm resulted in a more reactive animal when exposed to an open-field environment. Other investigators have also reported similar activity decrements after exposure to shock (Bindra \& Palfai, 1967; Atrens \& Bronstein, 1968). This is consistent with the position that a tone control is not an appropriate control for the 
evaluation of Pavlovian conditioned stimuli (Rescorla, 1969).

\section{REFERENCES}

AITKEN, P. Fear level and rats' open-field activity and defecation. Psychonomic Science, 1970, 19, 275-276.

ATRENS, D. M., \& BRONSTEIN, P. M Conditioned inhibition of exploration in young rats. Psychonomic Science, 1968 , 1. 309-310.

BINDRA, D., \& PALFAI, T. Nature of positive and negative incentive-motivational effects on general activity. Journal of Comparative \& Physiological Psychology, 1967, 63,
288-297.

BULL, J. A., \& OVERMIER, J. B. Additive and subtractive properties of excitation and inhibition. Journal of Comparative \& Physiological Psychology, 1968, 66. 511-514.

LIVESEY, P. J., \& EGGER, G. J. Age as a factor in open field responsiveness in the white rat. Journal of Comparative \& Physiological Psychology, 1970. 73, 93-99.

MONTGOMERY, $K$. $C$. The relation between fear induced by novel stimulation and exploratory behavior. Journal of Comparative \& Physiological Psychology, 1955, 48, 254-260.

RESCORLA, R. A. Pavlovian conditioned inhibition. Psychological Review, 1969, 72, 77-94.

RESCORLA R. A \& LOLORDO, V. M. Pavlovian inhibition of avoidance behavior. Journal of Comparative \& Physiological Psychology, 1965, 59, 406-412.

WEISMAN, R. G., \& LITNER, J. S. The course of Pavlovian excitation and inhibition of fear in rats. Journal of Comparative \& Physiological Psychology. 1969, 69, 667-672.

WEISMAN, R. G., \& LITNER, J. S. Role of the intertrial interval in Pavlovian differential conditioning of fear in rats. Journal of Comparative \& Physiological Psychology, 1971, 74, 211-218. 